\title{
The Genetic Network Controlling the Arabidopsis Transcriptional Response to Pseudomonas syringae pv. maculicola: Roles of Major Regulators and the Phytotoxin Coronatine
}

\author{
Lin Wang, ${ }^{1}$ Raka M. Mitra, ${ }^{1}$ Keegan D. Hasselmann, ${ }^{1}$ Masanao Sato, ${ }^{1,2}$ Lisa Lenarz-Wyatt, ${ }^{1}$ \\ Jerry D. Cohen, ${ }^{3}$ Fumiaki Katagiri, ${ }^{1}$ and Jane Glazebrook ${ }^{1}$ \\ ${ }^{1}$ Department of Plant Biology, Microbial and Plant Genomics Institute, University of Minnesota, 1445 Gortner Avenue, \\ St. Paul 55108, U.S.A.; ${ }^{2}$ Department of Life Sciences, Graduate School of Arts and Sciences, The University of Tokyo, \\ Komaba 3-8-1, Meguro-ku, Tokyo 153-8902, Japan; ${ }^{3}$ Department of Horticultural Science, Microbial and Plant Genomics \\ Institute, University of Minnesota, 1970 Folwell Avenue, St. Paul 55108, U.S.A.
}

Submitted 24 June 2008. Accepted 11 August 2008.

\begin{abstract}
Expression profiling of wild-type plants and mutants with defects in key components of the defense signaling network was used to model the Arabidopsis network $24 \mathrm{~h}$ after infection by Pseudomonas syringae pv. maculicola ES4326. Results using the Affymetrix ATH1 array revealed that expression levels of most pathogen-responsive genes were affected by mutations in coil, ein2, npr1, pad4, or sid2. These five mutations defined a small number of different expression patterns displayed by the majority of pathogenresponsive genes. $P$. syringae pv. tomato strain DC3000 elicited a much weaker salicylic acid (SA) response than ES4326. Additional mutants were profiled using a custom array. Profiles of $p b s 3$ and $n d r 1$ revealed major effects of these mutations and allowed $P B S 3$ and $N D R 1$ to be placed between the EDS1/PAD4 node and the SA synthesis node in the defense network. Comparison of coil, dde2, and jar1 profiles showed that many genes were affected by coil but very few were affected by dde2 or jar1. Profiles of coil plants infected with ES4326 were very similar to those of wild-type plants infected with bacteria unable to produce the phytotoxin coronatine, indicating that, essentially, all COI1-dependent gene expression changes in this system are caused by coronatine.
\end{abstract}

The current consensus model of plant-biotroph interactions may be most easily understood in an evolutionary framework. Originally, plant defense responses were activated as a consequence of recognition of molecules characteristic of microbes (pathogen-associated molecular patterns [PAMPs]) by pattern recognition receptors (PRR), resulting in PAMP-triggered immunity (PTI). Subsequently, pathogens acquired effectors,

Corresponding author: J. Glazebrook; Telephone: 612-624-5194; Fax: 612-624-6264; E-mail: jglazebr@umn.edu

Current address of K. D. Hasselmann: Division of Biostatistics, School of Public Health, University of Minnesota, A460 Mayo Building, 420 Delaware St. SE, Minneapolis 55455, MN, U.S.A.

Current address of Raka M. Mitra: Department of Biology, Carleton College, One North College Street, Northfield, MN 55057, U.S.A.

* The $\boldsymbol{e}$-Xtra logo stands for "electronic extra" and indicates that 10 supplementary tables are published online. which are proteins or small molecules transported into host cells that promote virulence. Many of these effectors function to suppress PTI. Ultimately, plants acquired resistance $(R)$ genes that recognize effectors, or host proteins modified by effectors, and trigger an alternative signaling cascade that actives plant defense responses. This response is known as effector-triggered immunity (ETI). The outcome of an interaction between a well-adapted pathogen and its host depends on the balance between the ability of pathogen effectors to turn off host defenses and the ability of the host to recognize the pathogen and activate defense responses (Jones and Dangl 2006).

The regulatory network that translates signals from PRR and $R$ genes into activation of plant defense responses can be thought of as several interconnected sectors. The PTI sector includes a mitogen-activated protein kinase cascade, WRKYclass transcription factors, and AtRbohD, an NADPH oxidase required for a membrane-associated oxidative burst and callose deposition (Asai et al. 2002; Chinchilla et al. 2007; GomezGomez and Boller 2000; Heese et al. 2007; Zhang et al. 2007; Zipfel et al. 2004). The salicylic acid (SA) sector is activated by ETI and by virulent pathogens that do not appear to trigger $R$ gene recognition. SA activation by virulent pathogens may be due to weak recognition by $R$ genes. PAMP recognition also activates SA signaling, and the SA sector is important for PTI (Tsuda et al. 2008). The jasmonic acid (JA) and ethylene (ET) sectors also have major effects on signaling during defense responses. JA and ET signaling tend to be important for resistance to necrotrophic pathogens and contribute little to resistance to biotrophs, although this is clearly an oversimplification (Glazebrook 2005). There is mutual negative cross-talk between JA and SA signaling but there is also evidence that JA, ET, and SA signaling may sometimes act synergistically (Mur et al. 2006; Schenk et al. 2000). Other plant hormones once thought of as mainly affecting development also impact defense signaling pathways (Robert-Seilaniantz et al. 2007). Abscisic acid (ABA) inhibits defense against Pseudomonas syringae, auxin inhibits SA signaling, and gibberellic acid (GA) may inhibit JA/ET signaling (de Torres-Zabala et al. 2007; Navarro et al. 2006; Robert-Seilaniantz et al. 2007).

Several major components of the SA sector are known. EDS1 and PAD4 are lipase-like proteins, but lipase activity does not seem to play a role in their functions. They interact physically and contribute to activation of SA synthesis in 
response to many, but not all, SA-inducing pathogens (Aarts et al. 1998; Falk et al. 1999; Feys et al. 2001, 2005; Jirage et al. 1999; Wiermer et al. 2005; Zhou et al. 1998). PAD4 is also required for pathogen-induced expression of many SA-independent genes (Glazebrook et al. 2003). SID2 and EDS5 are required for SA synthesis. SID2, also known as EDS16, is isochorismate synthase, an enzyme in the SA biosynthetic pathway, and EDS5 is a MATE transporter whose role in SA synthesis is not understood (Nawrath and Metraux 1999; Nawrath et al. 2002; Volko et al. 1998; Wildermuth et al. 2001). PBS3 is a member of the GH3-like family, which includes JAR1, a protein known to produce JA-Ile, the active form of JA. There are conflicting reports regarding SA levels in pbs 3 mutants after infection by various $P$. syringae strains, but it seems clear that SA levels are generally lower than in wild-type plants and that the enhanced susceptibility to $P$. syringae and reduced expression of the SA-responsive gene $P R-1$ can be rescued by exogenous SA (Jagadeeswaran et al. 2007; Lee et al. 2007; Nobuta et al. 2007). NPR1 transmits the SA signal to the nucleus. At low SA levels, it exists as a cytoplasmic oligomer (Kinkema et al. 2000; Mou et al. 2003). In response to the altered redox state caused by rising SA levels, it becomes a monomer, translocates to the nucleus, and mediates changes in gene expression through interaction with TGA-family transcription factors (Cao et al. 1997; Despres et al. 2000; Dong 2004; Mou et al. 2003; Zhang et al. 1999). WRKY-family transcription factors are also involved in NPR1-dependent changes in gene expression (Li et al. 2004, 2006; Wang et al. 2006).

Within the JA sector, most of the components involved in JA synthesis are known (Wasternack 2007). The active form of JA is JA-Ile, produced by the GH3-like enzyme JAR1 (Staswick and Tiryaki 2004; Thines et al. 2007). JA-Ile binds to the E3 ubiquitin ligase F-box protein COI1, thereby promoting ubiquitination and degradation of a small family of JAZ proteins (Katsir et al. 2008). JIN1 is an MYC2 transcription factor that is induced by JA and which controls expression of some JAresponsive genes (Lorenzo et al. 2004). P. syringae produces coronatine, a toxin that mimics JA-Ile by binding to COI1 (Thines et al. 2007). This is thought to promote virulence of $P$. syringae by interfering with SA signaling through the negative effect of JA on the SA sector, and by easing bacterial entry through inhibition of stomatal closure (Brooks et al. 2005; Melotto et al. 2006).

Most of what is known about the topology of the defense signaling network is based on comparing the effects of various defense signaling mutants on a few particular phenotypes. Considering the large number of genes induced or repressed in response to pathogen attack and the apparent complexity of the signaling network, a comparison of mutant phenotypes on a larger scale is desirable. One method for obtaining systemwide information about mutant phenotypes is expression profiling. Expression profiling has been used in studies of responses to pathogens; for example, to describe the response to PAMPs (Navarro et al. 2004), to discern the defense-suppressing activities of effectors (Truman et al. 2006), and to characterize particular defense-signaling mutants, such as mpk4 (Petersen et al. 2000) and pmr4 (Nishimura et al. 2003). Previously, we used expression profiling to model the defense network by comparing similarities among the profiles of a suite of defense signaling mutants (Glazebrook et al. 2003). This work was limited by the use of an early microarray representing only 8,000 Arabidopsis genes and by the lack of statistical power due to the absence of replicates. The data analysis considered only genes that were induced by infection.

Here, we report studies of the Arabidopsis response to infection by $P$. syringae pv. maculicola ES4326 at $24 \mathrm{~h}$ after infection. We used expression profiling of wild-type plants and mu- tants with defects in key defense-signaling components (coil, ein2, pad4, npr1, and sid2) to define the major patterns of regulation governing the response to this pathogen, thereby creating a model of the defense network at a single timepoint. The model describes the relationships among the regulators and defines groups of genes that are subject to similar regulation. We found that most induced genes fit one of a small number of regulatory patterns defined by the effects of the five mutations. The repressed genes fit similar patterns, demonstrating that these five genes comprise a regulatory network that controls activation of induced genes, as well as suppression of repressed genes. Comparison of our data obtained with strain ES4326 to public data obtained with other strains suggested that $P$. syringae pv. tomato DC3000 induces a much weaker SA response than ES4326. We found that this is true, because SA levels in plants infected with DC3000 are much lower than in plants infected with ES4326. We refined the network model by profiling additional mutants, revealing major effects of PBS3 and NDR1 on signaling, and allowing us to place these mutants between the node defined by PAD4 and EDS1 and the SA-synthesis node. Finally, we found that essentially all of the COI1-dependent gene expression changes in this system are due to the phytotoxin coronatine.

\section{RESULTS}

\section{A major portion of the Arabidopsis genome responds to infection by strain ES4326.}

To obtain a global view of gene expression changes triggered by $P$. syringae pv. maculicola ES4326 infection, we compared expression profiles of wild-type Col-0 plants infected with ES4326 to profiles of mock-infected plants. The experiment consisted of three independent biological replicates, each including samples collected 9, 24, and $32 \mathrm{~h}$ after infection. We obtained expression profiles from each of the resulting 18 samples using the Affymetrix ATH1 microarray (Redman et al. 2004). To determine which genes showed significantly different expression levels in corresponding mock- and ES4326infected samples, we used a mixed-effect linear model with a $q$ value cut-off of 0.01 , as described below. The $q$ value cut-off of 0.01 corresponds to a false discovery rate (FDR) of $1 \%$, excluding most genes that are not differentially expressed. We identified 381, 4,076, and 3,340 ES4326-induced genes and 210, 4,541, and 3,983 ES4326-repressed genes at 9, 24, and 32 $\mathrm{h}$ after infection, respectively.

The sets of induced or repressed genes from different timepoints overlapped extensively (Fig. 1). These similarities were reflected in the correlations for pairwise comparisons of the $\log _{2}$ fold-change values of the differentially expressed genes. For the set of 591 genes differentially expressed at $9 \mathrm{~h}$ postinoculation (hpi), the correlations between the 9 hpi values and the 24 and 32 hpi values were 0.81 and 0.88 , respectively. For the 9,993 genes differentially expressed at 24 or $32 \mathrm{hpi}$, the correlation between the 24 and 32 hpi values was 0.89 . The data for all the genes on the array are shown in Supplementary Table S1.

\section{Most $P$. syringae pv. maculicola ES4326-responsive genes show altered expression in defense signaling mutants.}

Sectors of the defense signaling network defined by the hormones SA, JA, and ET have major roles in regulating pathogen-responsive gene expression. To assess the contributions of these sectors on the gene expression changes induced by ES4326 infection, we compared expression profiles of wildtype Col-0 to those of various defense signaling mutants: pad4 (blocks SA and other signals), sid2 (blocks SA synthesis), nprl (blocks transmission of the SA signal), ein2 (blocks ET signal- 
ing), and coil (blocks JA signaling). The experiment above revealed the largest number of expression changes at $24 \mathrm{~h}$ after infection; therefore, we chose this timepoint for mutant analysis. The experiment consisted of three independent biological replicates, each including wild-type plants that were mock in-
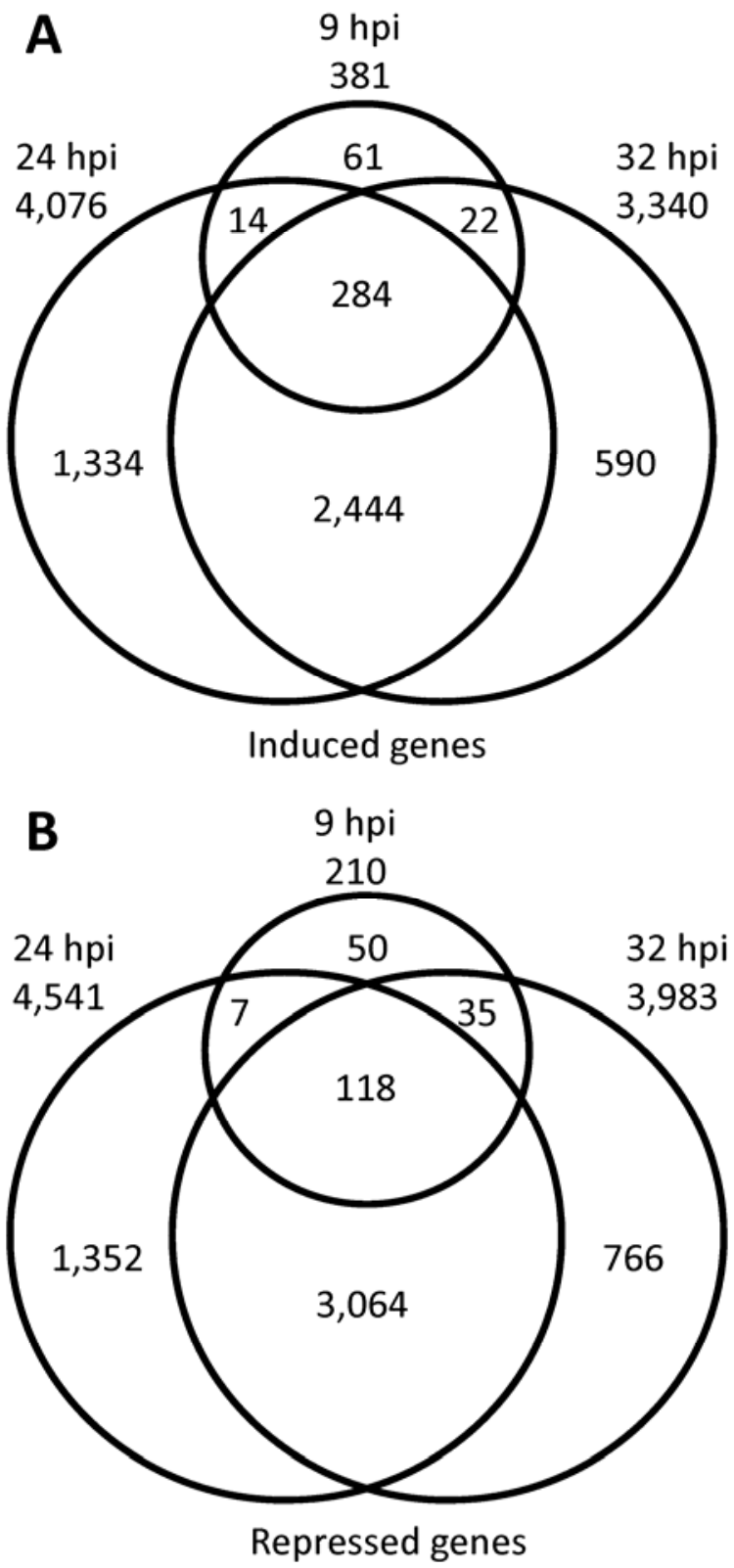

Fig. 1. Venn diagrams showing the number of genes whose expression levels are affected by Pseudomonas syringae pv. maculicola ES4326 infection. The total number of genes induced or repressed at each timepoint is shown outside the circles; hpi = hours postinoculation. A, Induced genes. B, Repressed genes. oculated or ES4326 infected and mutants that were ES4326 infected, all sampled after $24 \mathrm{~h}$. We obtained expression profiles from each of these 21 samples using the ATH1 microarray.

We decided to focus on a set of genes that show robust expression changes in response to ES4326 infection. To define these, we analyzed the profiles from all six samples of mockinoculated and ES4326-infected wild-type plants 24 hpi (three from the time course experiment and three from the signaling mutants experiment), using a mixed-effect linear model. Results for all the genes on the array are shown in Supplementary Table S2. We first selected genes that were differentially expressed with $q$ values $<0.01$. Then, to eliminate genes with small expression changes, we further selected genes that showed a greater than fourfold change in expression, resulting in a final set of 1,140 ES4326-induced and 1,397 ES4326-repressed genes, for a total of 2,537 .

To determine which of the 2,537 genes induced or repressed by ES4326 showed altered expression levels in plant defense signaling mutants, we compared profiles from infected wildtype plants with those of infected mutants. Expression levels in infected wild-type plants were compared with those in infected mutant plants using a mixed-effect linear model. Supplementary Table S3 contains the data for all the genes on the array. For each mutant, we determined which of the 1,140 or 1,397 genes induced or repressed by ES4326 infection in wild-type plants showed significantly different expression levels in mutant plants, using a $q$ value cut-off of $q<0.01$. We did not include a fold-change criterion, because we wanted to include genes that were only modestly affected by one or more mutations. Although all mutations studied altered expression of some ES4326-responsive genes, the mutation with the strongest effect on both induced and repressed genes was pad4, which reduced expression of 710 of 1,140 induced genes and increased expression of 897 of 1,397 repressed genes (Table 1).

For the vast majority of genes differentially expressed between infected mutants and infected wild type, defense signaling mutations reduced ES4326-triggered expression changes. For ES4326-induced genes, nearly all effects of mutations were reductions of gene expression, indicating that the signaling factors act to induce expression of these genes. For ES4326repressed genes, nearly all effects of mutations were increases of gene expression, indicating that the signaling factors act to repress expression of these genes.

\section{The gene circuits controlling gene induction and gene repression are similar.}

To define patterns of defense gene regulation and reveal relationships among network components, we sorted the induced genes into groups according to the defense signaling mutations that significantly $(q<0.01)$ affected their expression (Supplementary Table S4). Of the 1,140 induced genes, 189 were not affected by any mutation, indicating that they are controlled by network sectors other than those involving SA, JA, or ET or are controlled by these sectors in a redundant manner. Of the remaining 951 genes, 848 fit one of nine major

Table 1. Genes differentially expressed in mutant plants ${ }^{\mathrm{a}}$

\begin{tabular}{|c|c|c|c|c|c|c|}
\hline \multirow[b]{2}{*}{ Expression (total no. of genes) } & \multirow[b]{2}{*}{ Level $^{\text {b }}$} & \multicolumn{5}{|c|}{ Genes } \\
\hline & & pad4 & $\operatorname{sid2}$ & npr1 & $\operatorname{ein} 2$ & coil \\
\hline \multirow[t]{2}{*}{ Induced by infection $(1,140)$} & $\mathrm{L}$ & 710 & 153 & 220 & 177 & 349 \\
\hline & $\mathrm{H}$ & 14 & 28 & 24 & 2 & 4 \\
\hline \multirow[t]{2}{*}{ Repressed by infection $(1,397)$} & $\mathrm{L}$ & 0 & 3 & 1 & 0 & 7 \\
\hline & $\mathrm{H}$ & 897 & 111 & 317 & 167 & 239 \\
\hline
\end{tabular}

\footnotetext{
${ }^{\text {a }}$ For each mutant, the number of genes expressed at significantly different levels in infected mutant plants than in infected wild-type plants is shown. Data were obtained from the ATH1 microarray.
}

${ }^{\mathrm{b}} \mathrm{L}$ and $\mathrm{H}$ indicate genes expressed at lower and higher levels, respectively, in mutant than in wild-type plants $(q<0.01)$. 
patterns in which one or more mutations reduced expression (Fig. 2A). Three sets of genes were affected by only one mutation: pad4, coil, or ein2. In the remaining six patterns, multiple mutations affected gene expression. Three sets of genes were affected by pairwise combinations of pad4, coil and ein2; one set of genes was affected by all three mutations; one set of genes was affected by nprl and pad4; and the final set was affected by sid2, nprl, and pad4. Thus, genes affected by the SA-related mutations $n p r l$ and sid2 were distinct from genes affected by the JA- and ET-related mutations coil and ein2. The mutation in pad4 affected all the NPR1- or SID2-dependent genes and a subset of the COI1- or EIN2-dependent genes. The 103 genes that did not fit one of the major patterns represented 31 different minor patterns. The largest of these minor patterns were a set of 11 genes that were affected only by pad4 and sid 2 and a set of 11 genes that were affected only by $n p r l$ and sid2. Fewer than 10 genes fit each of the other minor patterns. Some minor patterns included genes that were expressed at higher levels in mutant plants than in wild-type plants. We conclude that the five signaling mutations studied affect expression of most of the genes induced by ES4326 infection and that the regulation of most genes can be described by one of nine major patterns.

To determine the extent of the similarity between the gene circuits controlling gene induction and gene repression, we carried out a similar analysis using the ES4326-repressed genes (Supplementary Table S5). Of the 1,397 repressed genes, 420 were not affected by any mutation (Fig. 2B). Of the remaining 977 genes, 891 fit one of nine major patterns. Six of these nine major patterns for repressed genes were also found as major patterns controlling the induced genes. The remaining three major patterns with the smallest number of induced genes (ein 2 only, pad 4 and ein 2 only, and coil and ein 2 only) were minor patterns among the repressed genes. The repressed genes showed three additional major patterns that were minor or nonexistent among the induced genes: genes affected by all mutations $(n=17)$, genes affected by all mutations except sid2 $(n=35)$, and genes affected by ein2, pad4, and $n p r l(n=30)$. Among the major patterns of repressed genes, these were the three with the smallest numbers of genes. The 86 repressed genes that did not fit in one of the major patterns represented 19 different minor patterns. These included 14 genes affected by coil, pad4, and nprl only; 13 affected by all mutations except coil; and 13 affected by ein 2 and pad 4 only. The other patterns included some in which genes were repressed even further than in wild-type plants, and comprised fewer than 10 genes each. Overall, the gene circuitry controlling gene repression was very similar to the one controlling induction, with a few differences: more repressed genes were unaffected by any mutation (420 versus 189), more repressed genes were affected only by pad4 (467 versus 337), and more repressed genes were affected by combinations of SA-related $n p r l$ or sid 2 mutations and JA- and ET-related mutations coil and ein2 (82 versus 21, all in minor classes).

\section{P. syringae pv. maculicola $\mathrm{ES4326}$ is a stronger inducer of the SA network sector than is $P$. syringae pv. tomato DC3000.}

$P$. syringae pv. maculicola ES4326 infection induces strong expression of the canonical SA-regulated gene $P R-1$ whereas $P$. syringae pv. tomato DC3000 induces very weak expression (Glazebrook et al. 1996; Ham et al. 2007). We tested the possibility that this is a reflection of a general difference in the activity of the SA network sector during infection by these two strains. Defense responses to different bacterial strains were compared using expression profiling data in the NASC-120 data set. This data includes expression profiles of wild-type
Col-0 plants $24 \mathrm{~h}$ after mock inoculation or inoculation with strains DC3000, DC3000 avrRpml (a strain that triggers ETI due to recognition of AvrRpm1 by the $R$ gene $R P M 1$ ), DC3000 $h r c C$ (the $h r c C$ mutation blocks secretion of effectors; therefore, this strain acts as an inducer of the PAMP response), and P. syringae pv. phaseolicola race 6 (a bean pathogen that fails to cause disease on Arabidopsis). The data were analyzed using a mixed-effect linear model, as described below. The $\log _{2}$ expression values, the $\log _{2}$ fold-change values, and the $q$ values for each pathogen compared with mock at $24 \mathrm{~h}$ are shown in Table S6. Any gene for which the $q$ value for the comparison of mock and pathogen inoculation was less than 0.01 was considered responsive to that pathogen, regardless of the fold change. We chose this less-stringent criterion to minimize false negatives when testing for ES4326-responsive genes that also respond to the other strains. DC3000 affected the most genes $(n=3,369)$ while DC3000 hrcC affected the fewest $(n=1,660)$ (Table 2$)$. This is the expected result, because PAMP responses are rapid and are waning by $24 \mathrm{~h}$ after treatment (Navarro et al. 2004; Truman et al. 2006). DC3000 hrcC fails to deliver effectors and grows much less than DC3000, which may also contribute to differences in gene expression.

SA-dependent responses are critical for resistance to $P$. $s y$ ringae (Glazebrook 2005). Consequently, we examined induction of SA-dependent genes, defined as the 107 genes that are induced by ES4326 in a PAD4-, NPR1-, and SID2-dependent manner, by the other pathogen strains. We found that DC3000 induced the fewest of these genes $(n=30)$ (Table 2). Further-
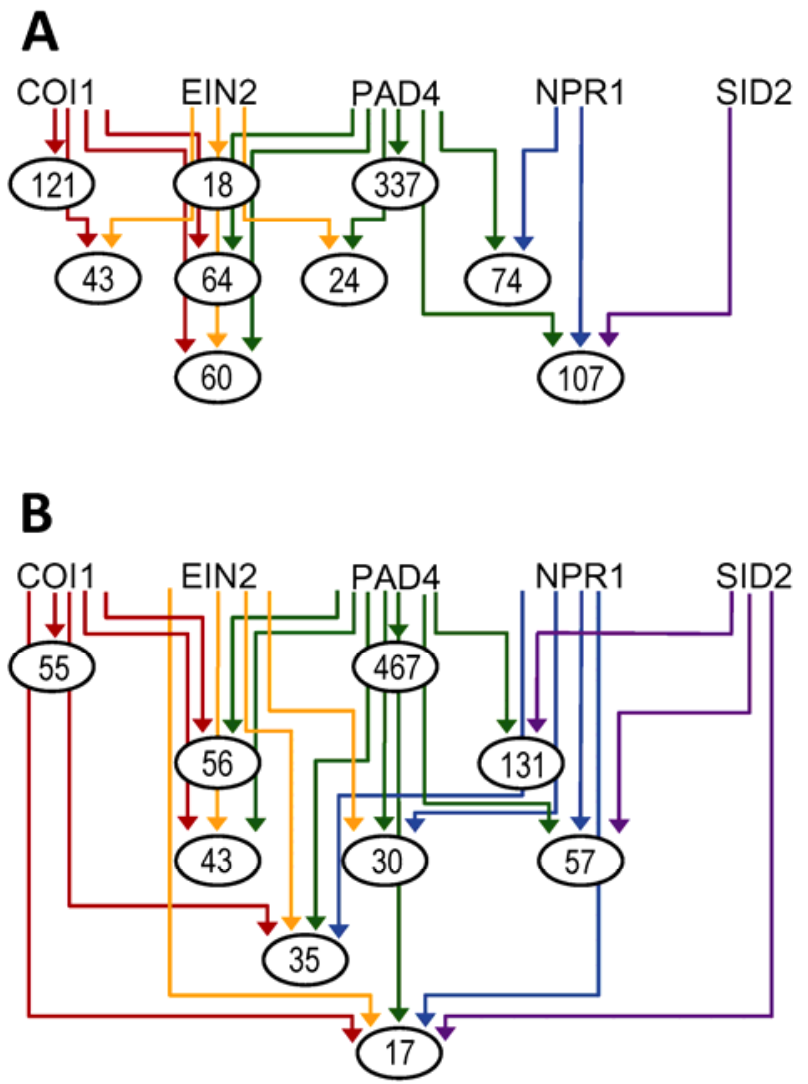

Fig. 2. Pseudomonas syringae pv. maculicola ES4326-responsive genes that are controlled by major defense signaling genes. Numbers in ovals indicate the number of genes whose induction or repression is compromised by mutation in certain regulators. For example, A shows that the induction of 337 genes was compromised in pad4 but not in any other mutants tested. The induction of 74 additional genes was compromised in only pad4 and npr 1 mutants. A, Induced genes. B, Repressed genes. 
more, the average DC3000-induced $\log _{2}$ fold-change of the 107 genes was very low compared with the averages induced by the other strains ( 0.6 compared with $>1$ for all the other strains) (Table 2). To test whether this effect was specific to SA-dependent genes, we carried out a similar analysis on the entire set of 1,140 genes strongly induced by ES4326. In marked contrast to the results with the 107 SA-induced genes, DC3000 and DC3000 avrRpml induced the largest number of these genes (831 and 835, respectively), with fewer genes induced by $P$. syringae pv. phaseolicola or $P$. syringae pv. tomato DC3000 hrcC. Similarly, the average $\log _{2}$ fold-change values for these 1,140 genes were highest for these two strains (1.90 for DC3000 and 1.86 for DC3000 avrRpm1) (Table 2). The difference in induction of SA-dependent genes in DC3000- versus ES4326-infected plants is unlikely to be due solely to differences in infection conditions for two reasons. First, DC3000 was a weaker inducer of SA-dependent genes when compared with other strains within the NASC-120 data set, not just when compared with ES4326. Second, the difference in expression of SA-dependent genes between DC3000 and ES4326 was much more pronounced than the difference for the complete set of ES4326-induced genes.

The results from microarray analysis demonstrated that SAdependent gene expression is less active in DC3000-infected plants than in ES4326-infected plants, suggesting that SA levels might be lower in DC3000-infected plants. To test this idea, we assayed SA in wild-type, pad4, and sid2 plants 9 and 24 hpi. SA levels were dramatically lower in DC3000-infected plants than in ES4326-infected plants (Fig. 3). We conclude that our inference from microarray data is correct. DC3000 either actively represses or avoids inducing the strong SA response induced by ES4326.

\section{Exploration of the SA and JA network sectors using the miniarray.}

The SA and JA network sectors are known to play major roles in disease resistance (Glazebrook 2005). To define the roles of additional signaling components in these sectors, we selected mutants known, or which we thought likely, to have defects in SA or JA signaling. We then profiled these mutants $24 \mathrm{~h}$ after infection by strain ES4326, using a custom microarray that monitors expression of 464 pathogen-responsive genes, which we call a "miniarray" (Sato et al. 2007). For SA signaling, we chose eds 1 because the amino acid sequence of EDS1 is similar to PAD4, EDS1 and PAD4 physically interact, and eds 1 mutants have reduced SA levels (Falk et al. 1999; Feys et al. 2001); eds5 because eds5 mutants have SA levels as low as those in sid2 and EDS5 is thought to be required for SA synthesis (Nawrath and Metraux 1999; Nawrath et al. 2002); pbs 3 because some groups have reported that SA levels are low in pbs3 plants (Jagadeeswaran et al. 2007; Lee et al. 2007); fmol because pathogen-induced FMOlexpression is under EDS1 and PAD4 control and fmol mutants are defective in systemic acquired resistance, an SA-requiring process (Bartsch et al. 2006; Mishina and Zeier 2006); and $n d r l$ be- cause we recently found that an $n d r l$ mutation has a major effect on gene expression changes triggered by infection with DC3000 avrRpt2, raising the possibility of an SA signaling defect (Sato et al. 2007). We also profiled pad4, nprl, and sid2. For JA signaling, we chose $d d e 2$, a mutation in allene oxide synthase that blocks JA synthesis (von Malek et al. 2002); jarl, a mutation in a JA-conjugating enzyme that blocks production of JA-isoleucine (Staswick and Tiryaki 2004); jinl, a mutation in the MYB2 transcription factor required for a subset of responses to JA (Lorenzo et al. 2004); and coil, a mutation in an E3-ubiquitin ligase required for JA signaling (Xie et al. 1998). As in our experiments using the ATH1 microarray, wild-type plants were mock inoculated or inoculated with ES4326 and mutant plants were inoculated with ES4326. Samples for profiling were collected after $24 \mathrm{~h}$. Each experiment included three independent biological replicates and data were analyzed using mixed-effect linear models as described below.

We defined genes responding to ES4326 infection in wildtype plants using data from two experiments, each consisting of three replicates each of mock- and ES4326-inoculated wildtype plants. The $\log _{2}$ expression values, the $\log _{2}$ fold-change values, and the $q$ values for all the genes on the array are

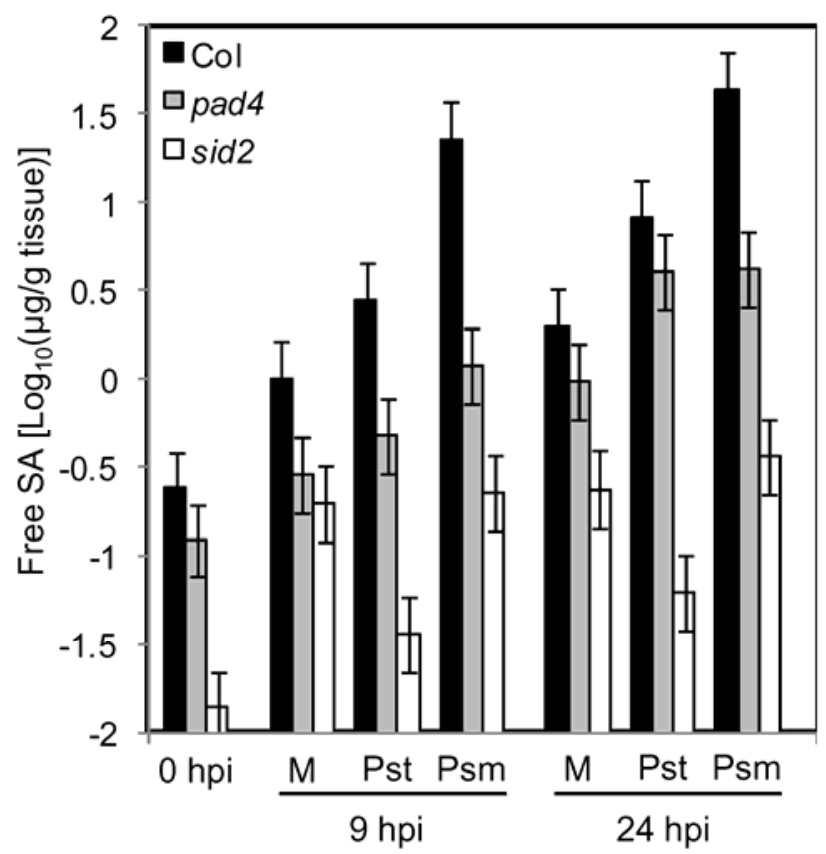

Fig. 3. Salicylic acid (SA) levels in plants infected with Pseudomonas syringae pv. tomato DC3000 or P. syringae pv. maculicola ES4326. Plants were mock inoculated (M) or inoculated with DC3000 (Pst) or ES4326 (Psm), and sampled 9 or $24 \mathrm{~h}$ postinoculation (hpi). Uninoculated plants were sampled at the beginning of the experiment $(0 \mathrm{hpi})$. Each bar represents the mean and standard error of SA levels from two independent experiments, calculated by analysis of variance. Note the $\log _{10}$ scale on the y-axis. At both 9 and $24 \mathrm{~h}$, SA levels in wild-type (Col-0) plants were much lower after DC3000 inoculation than after ES4326-inoculation $(P<0.01)$.

Table 2. Induction of Pseudomonas syringae pv. maculicola ES4326-induced genes by other $P$. syringae strains

\begin{tabular}{|c|c|c|c|c|c|}
\hline Strains & $\begin{array}{c}\text { Total no. of genes } \\
\text { induced } \\
(q<0.01)\end{array}$ & $\begin{array}{c}\text { No. of } 107 \\
\text { salicylic acid (SA)- } \\
\text { dependent genes } \\
\text { induced } \\
(q<\mathbf{0 . 0 1})\end{array}$ & $\begin{array}{l}\text { Average } \log _{2} \text { fold- } \\
\text { change of } 107 \mathrm{SA}- \\
\text { dependent genes } \\
\text { (infected vs. mock) }\end{array}$ & $\begin{array}{c}\text { No. of } 1,140 \\
\text { ES4326-induced } \\
\text { genes induced } \\
(q<0.01)\end{array}$ & $\begin{array}{c}\text { Average } \log _{2} \text { fold- } \\
\text { change of } 1140 \\
\text { ES4326-induced } \\
\text { genes } \\
\text { (infected vs. mock) }\end{array}$ \\
\hline P. syringae pv. maculicola ES4326 & 4,076 & 107 & 2.91 & 1,140 & 3.12 \\
\hline P. syringae pv. tomato $\mathrm{DC} 3000$ & 3,369 & 31 & 0.60 & 831 & 1.90 \\
\hline P. syringae pv. tomato DC3000 avrRpml & 2,438 & 50 & 1.14 & 835 & 1.86 \\
\hline P. syringae pv. tomato DC3000 hrcC & 1,660 & 55 & 1.10 & 443 & 0.86 \\
\hline P. syringae pv. phaseolicola & 2,170 & 81 & 1.70 & 637 & 1.27 \\
\hline
\end{tabular}


shown in Supplementary Table S7. ES4326-responsive genes were selected by requiring a $\log _{2}$ fold-change of $<-1$ or $>1$ (twofold) and $q<0.05$, resulting in 223 genes. These criteria are less stringent than the criteria we used to define ES4326responsive genes on the ATH1 array. They were chosen because the miniarray is less sensitive than the ATH1 array (Sato et al. $2007)$ and the smaller number of genes monitored reduces the number of false positives $(q<0.05$ with 223 genes will detect an average of 11 false positives). To detect the effects of mutations on gene expression, we compared expression levels in mutant and wild-type plants, as shown in Supplementary Table S8. Then, among the 223 ES4326-responsive genes, we selected those whose expression levels in ES4326-infected plants were significantly altered by least one mutation $(q<0.05)$, resulting in 205 genes. The $\log _{2}$ fold-change and $q$ values for these 205 genes are shown in Supplementary Table S9. The number of genes affected by each mutation is shown in Table 3 . To explore the relationships among the mutations, the $\log _{2}$ fold-change values for each mutation versus wild type were subjected to complete linkage hierarchical clustering using Cluster, and the results were visualized using Treeview (Fig. 4) (Eisen et al. 1998). Correlations between the $\log _{2}$ fold-change values for each pair of mutants are shown in Table 4. Beginning with the SA signaling mutants, we used the results to define the functions of signaling components relative to those of PAD4, NPR1, SID2, and COI1.

EDS1: The profile of eds 1 was more similar to that of pad4 than to any other mutation in our set (correlation 0.84) (Table 4). The hierarchical clustering does not show any large groups of genes that are affected differently by these two mutations. Growth of ES4326 in $e d s 1$ was similar to pad4, with bacterial titers approximately 300-fold higher than in wild-type plants (Fig. 5A). We conclude that, within the limits of resolution of our analysis, EDS1 and PAD4 affect the same function.

EDS5 and NPR1: The profiles of eds5, nprl, and sid2 are all very similar to each other (correlations eds 5 to $n p r l$, eds 5 to sid2, and $n p r l$ to $\operatorname{sid} 2=0.84,0.81$, and 0.78 , respectively) (Table 4). These mutations also appear to define the same function, which is presumably the activity of SA. In the ATH1 data, we observed a group of 74 genes whose induction required NPR1 but not SID2, seemingly contradicting the results from the miniarray. Only three of these genes are represented on the miniarray and only one of them met the criteria for significant induction in wild-type plants. Thus, the miniarray cannot detect the group of genes whose induction requires NPRI but not SID2.

FMO1: In fmol, expression of only one gene, FMO1 itself (At1g19250), was significantly altered. Hierarchical clustering did not detect a close similarity between fmol and any of other mutants studied (Fig. 4). We conclude that fmol does not have a major effect on gene expression $24 \mathrm{~h}$ after ES4326 infection. Mishina and Zeier reported that fmol is not more susceptible to infection by ES4326 (Mishina and Zeier 2006) but we found a modest increase in susceptibility to ES4326 (Fig. 5A). This discrepancy could be due to differences in growth conditions between laboratories.

PBS3: The expression profile of $p b s 3$ was similar to those of edsl (correlation 0.59), pad4 (0.68), nprl (0.71), eds5 (0.71), and sid2 (0.51) (Table 4). The number of genes affected by $p b s 3$ was greater than the number affected by $n p r l$, eds 5 , or sid 2 but smaller than the number affected by eds 1 or pad4 (Table 3). Cluster grouped pbs3 with pad4 and $e d s 1$, in a separate group from $n p r 1$, eds5, and sid2 (Fig. 4) Inspection of Figure 4 explains these results. There is a group of genes that is affected similarly by $p b s 3$, eds 1 , and pad4 but not by $n p r l$, eds 5 , or sid2 (Fig. 4, group A). There are other groups of genes that are affected by pad4 and eds 1 but not by pbs3, nprl, eds5, or sid 2 (Fig. 4, groups B and C). We found a major increase in susceptibility to ES4326 in pbs3 (Fig. 5B), consistent with the results of Nobuta and associates (2007). Assuming that signal flow through the network is divergent, we conclude that $P B S 3$ acts at a point intermediate between the node defined by pad 4 and $e d s 1$ and the node defined by $n p r l, e d s 5$, and sid 2 .

NDRl: The expression profile of $n d r l$ is very similar to those of $e d s 1$ and pad4 (correlations of 0.79 and 0.75 , respectively), and slightly less similar to pbs3 (correlation of 0.69 ). Correlations between $n d r l$ and $e d s 5$ or sid 2 are low, less than 0.40 . Hierarchical clustering places $n d r l$ in the group with $p b s 3, e d s 1$, and pad4, closer to $e d s 1$ and pad4 than to pbs3. Inspection of Figure 4 reveals a small group of genes (group C) affected by pad4 and eds 1 but not by $n d r l$ or $p b s 3$. Another group of genes (group B) is affected by pad4, eds1, and $n d r 1$ but not by $p b s 3$. There are no groups of genes affected by $p b s 3$ but not $n d r 1$; therefore, we conclude that NDR1 likely acts at a point between the node defined by PAD4 and EDS1 and the node defined by $P B S 3$.

\section{COI1-dependent gene expression changes are a response to coronatine.}

We studied three additional mutations affecting the JA sector. Two of these, dde 2 and jarl, block synthesis of the active form of JA, JA-Ile. COII is required for responses to JA. Consequently, if endogenous JA-Ile is responsible for activation of the COI1-dependent genes, the profiles of $d d e 2$, jarl, and coil should all be quite similar. Our results from the miniarray are strikingly inconsistent with this idea, because very few genes were significantly affected by dde $2(n=16)$ or jarl $(n=9)$, whereas many were affected by coil $(n=96)$. Furthermore, there was almost no correlation between the profile of coil and those of $d d e 2$ and jarl ( -0.17 and 0.15 , respectively). This raised the possibility that coronatine, a toxin produced by ES4326 and DC3000 that mimics the effects of JA-Ile, might be responsible for induction of the COI1-dependent genes.

To study the role of coronatine in ES4326-induced gene expression, we profiled wild-type and coil plants after mock inoculation, inoculation with ES4326, or inoculation with ES4326 cor, a coronatine-deficient mutant. The experiment consisted of three biological replicates and data were analyzed using

Table 3. Genes differentially expressed in mutant plants ${ }^{\mathrm{a}}$

\begin{tabular}{|c|c|c|c|c|c|c|c|c|c|c|c|c|c|}
\hline \multirow[b]{2}{*}{ Genes $(\text { no. })^{b}$} & \multirow[b]{2}{*}{ Level $^{c}$} & \multicolumn{12}{|c|}{ Mutants } \\
\hline & & coil & dde2 & eds1 & eds 5 & fmol & jin1 & jarl & $n d r 1$ & npr1 & pad4 & $p b s 3$ & sid 2 \\
\hline \multirow[t]{2}{*}{ Induced in WT (177) } & $\mathrm{L}$ & 74 & 9 & 88 & 22 & 1 & 8 & 7 & 57 & 25 & 103 & 56 & 22 \\
\hline & $\mathrm{H}$ & 11 & 4 & 8 & 3 & 0 & 0 & 2 & 11 & 3 & 10 & 19 & 4 \\
\hline \multirow[t]{2}{*}{ Repressed in WT (28) } & $\mathrm{L}$ & 0 & 3 & 0 & 0 & 0 & 0 & 0 & 4 & 0 & 0 & 0 & 0 \\
\hline & $\mathrm{H}$ & 11 & 0 & 16 & 0 & 0 & 1 & 0 & 5 & 3 & 10 & 16 & 1 \\
\hline
\end{tabular}

${ }^{\text {a }}$ For each mutant, the number of genes expressed at significantly different levels in infected mutant plants than in infected wild-type (WT) plants is shown. Data were obtained from the miniarray.

${ }^{\mathrm{b}}$ Number in parentheses $=$ total number of genes expressed.

${ }^{\mathrm{c}} \mathrm{L}$ and $\mathrm{H}$ indicate genes expressed at lower and higher levels, respectively, in mutant than in wild-type plants $(q<0.05)$. 
mixed-effect linear models, as described below. Using this data, we compared two sets of $\log _{2}$ fold-change data for all the genes on the array; coilinfected with ES4326 versus wild type infected with ES4326 and wild type infected with ES4326 cor versus wild type infected with ES4326 (Supplementary Table $\mathrm{S} 10)$. These values are almost identical, with a correlation of 0.96 (Fig. 6). We conclude that essentially all of the COIdependent gene expression changes triggered by ES4326 at

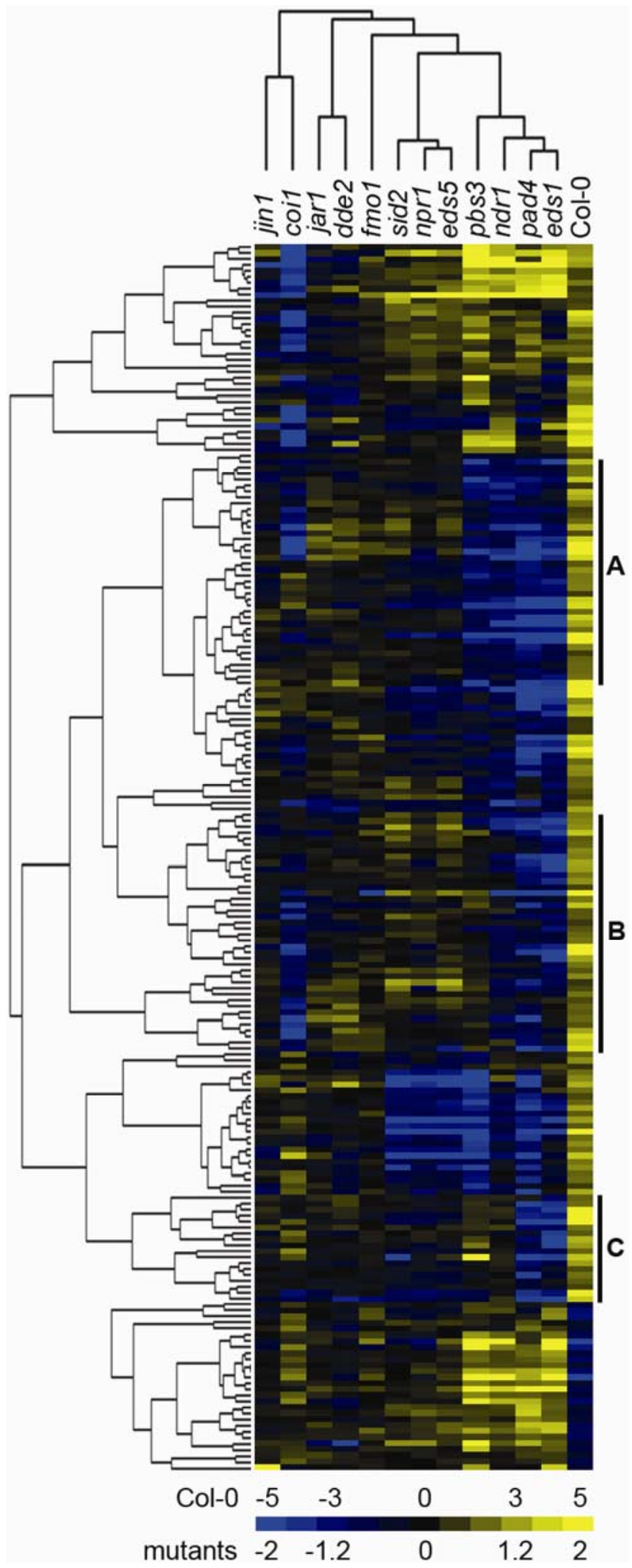

$24 \mathrm{~h}$ after infection are a response to coronatine produced by the pathogen.

\section{$D D E 2, J A R 1$, and JIN1 have small effects} on coronatine responses.

Although dde2 and jarlaffect only a small number of genes, there is a reasonable correlation between their profiles $(0.58)$ (Table 4). Among the 22 genes significantly affected by at least one of these mutants, the correlation is 0.75 , suggesting that endogenous JA-Ile contributes to changes in expression of a small group of genes. Curiously, for the 16 genes significantly affected by $d d e 2$, the correlation between coil and $d d e 2$ is -0.72 , suggesting that endogenous JA-Ile is inhibiting COI1. Nine genes were significantly affected by jinl. Of these nine genes, five are similarly affected by coil and four are not. This suggests that JINI mediates a small fraction of the gene expression changes triggered by the action of COI1. The four genes that are not affected by coil may indicate a COI1-independent function of JIN1 but this data set is too small to draw a firm conclusion.

\section{DISCUSSION}

In this work, we used similarities among expression profiles from plants with loss-of-function mutations in key components of the defense signaling network to study the network at a fixed time after infection with a particular pathogen, ES4326. We found that most ES4326-responsive genes were affected by at least one mutation in the study set and that most affected genes fit one of a few simple patterns of regulation. Comparison of the ES4326 profiling data with profiles from DC3000infected plants indicated that the SA sector is much less active after DC3000 infection. Expansion of the set of mutants studied using a custom miniarray allowed $E D S 1, N D R 1, P B S 3$, and EDS5 to be positioned in the SA sector. The lack of correlation between profiles from coil and those of $d d e 2$ and jarl led to an experiment that showed that essentially all COII-dependent gene expression changes are attributable to the effects of coronatine.

Profiling showed that expression levels of most (948 of 1,140) ES4326-induced genes were reduced by one or more of the mutations pad4, nprl, sid2, ein2, or coil. Most ES4326induced genes $(1,037$ of 1,140$)$ (Fig. 2A) fit 1 of 10 major expression patterns (including the pattern unaffected by any mutation), far fewer than the 32 possible patterns formed by all combinations of unaffected or reduced expression in each mutant. A few genes $(n=103)$ constituted 31 minor patterns, including some in which genes were induced at even higher levels in mutants than in wild-type plants. Some of the minor patterns are likely not biologically meaningful, because many of the genes constituting them were excluded from one of the major patterns by $q$ values close to the cut-off. Interestingly,

Fig. 4. Clustering of $\log _{2}$ fold-change values of mutants versus the wild type. Complete linkage hierarchical clustering was performed. Vertical dendrograms describe similarities among genes and the horizontal dendrogram describes similarities among mutants. Columns labeled by mutant names contain $\log _{2}$ fold-change values of mutants versus the wild type. The column labeled "Col-0" contains the $\log _{2}$ fold-change values of Pseudomonas syringae pv. maculicola ES4326-inoculated versus mock-inoculated wild-type plants. These values were not used in the clustering. Negative values shown in blue indicate lower expression in a mutant than in wild-type plants or repression in wild-type plants. Positive values shown in yellow indicate higher expression in a mutant than in wild-type plants or induction in wild-type plants. A color scale is provided at the bottom of the figure. Vertical bars at the right labeled "A", "B", or "C" mark clusters of genes that are discussed in the text. 
repression of many (976 of 1,397) of the ES4326-induced genes was attenuated by the same set of mutants, and the major expression patterns of repressed genes were quite similar to those of the induced genes. It is tempting to think of repressed genes as being targets of pathogen effectors whose repression favors the pathogen. However, for the many genes whose repression is attenuated by pad4, nprl, or sid2, this seems unlikely to be true. Rather, it is likely that the SA-dependent defense response includes increased expression of some genes and decreased expression of others.

We found that the SA network sector is much less active following DC3000 infection than following ES4326 infection. This could be due to better recognition of ES4326 by the plant or better suppression of SA signaling by DC3000 effectors. These possibilities might be distinguished by introducing individual effectors from each strain into the other, and screening for DC3000 effectors that weaken the SA response to ES4326 and for ES4326 effectors that strengthen the SA response to DC3000.

Using profiles from a custom miniarray, we found that pad4 and $e d s 1$ have very similar effects on network function that we could not differentiate, as did eds5, nprl, and sid2. We did differentiate nprl and sid2 using the ATH1 array but very few of the differentiating genes were present on the miniarray. We identified PBS3 and NDR1 as network components acting between the pad4/eds 1 node and the eds $5 /$ nprl/sid 2 node, as shown in Figure 7. NDR1 was placed above PBS3 in the network due to the group of genes affected by pad4, eds 1 , and $n d r 1$ but not by $p b s 3$ (Fig. 4, group B). PBS3 was placed above NPR1 due to the group of genes affected by pad4, eds1, $n d r 1$, and pbs3 but not by $n p r 1$ (Fig. 5, group A). NPR1 was placed above EDS5 and SID2 due to the group of genes identified on the ATH1 array that were affected by nprl but not by sid2. This placement may seem strange because NPR1 is well known to transmit the SA signal to the nucleus. Our model rests on the assumption of signal divergence through the network. This assumption may not be correct. Alternatively, NPR1 may react to a signal in addition to SA. This was suggested as an explanation for why an induced systemic resistance response required NPR1 but not SA (Pieterse et al. 1998). To explain our data, such an additional signal would have to require PAD4, EDS1, NDR1, and PBS3. We did not attempt to place fmol in the network, because we did not detect any significant changes in gene expression in this mutant.

PBS3 encodes a GH3-like protein. Because other family members, such as JAR1, catalyze formation of hormone-amino acid conjugates, it is tempting to speculate that PBS3 produces an SA conjugate. However, this is unlikely because the enhanced susceptibility and reduced $P R-1$ expression phenotypes of $p b s 3$ can be rescued by exogenous SA. There is conflicting data regarding levels of free (not glucoside conjugates) SA levels in infected pbs3 plants. Nobuta and associates (2007) reported increased SA $24 \mathrm{~h}$ after infection by DC3000 avrRpt2. Lee and associates (2007) reported reduced SA $24 \mathrm{~h}$ after infection by $P$. syringae pv. maculicola DG3 (very similar to ES4326), $6 \mathrm{~h}$ after infection by DG6 (a DG3 derivative carrying avrRpt2) and $24 \mathrm{~h}$ after infection by $P$. syringae pv. maculicola DG34 (a DG3 derivative carrying avrRpml). Jagadeeswaran and associates (2007) found reduced levels 12 and $24 \mathrm{~h}$ after infection by DC3000 carrying avrRpm1. Our profiling data strongly suggests reduced SA signaling $24 \mathrm{~h}$ after infection by ES4326, consistent with the reduced SA levels observed by Lee and associates (2007). It is entirely possible that all of the reported SA levels are correct and that the contribution of PBS3 to SA levels varies according to the inducing strain or with environmental conditions. This would be reminiscent of pad4, which shows reduced SA levels after ES4326 infection but not after ES4326 avrRpt2 infection (Zhou et al. 1998). Also like PAD4, PBS3 affects expression of many more genes than canonical SA signaling mutants. This suggests that the effect of $P B S 3$ on SA levels is regulatory rather than biosynthetic.

NDR I was first identified in a screen for mutations that interfere with resistance due to recognition of the AvrB effector by the R protein RPM1 (Century et al. 1995). Subsequently, it was found to be required for resistance mediated by many other, but not all, $R$ genes (Aarts et al. 1998; Century et al. 1995; McDowell et al. 2000). Based on these results, NDR1 has long been considered as a protein required for $R$-gene-mediated resistance. Indeed, expression profiling of responses to DC3000 avrRpt2 in wild-type, $n d r 1$, and rps 2 plants showed that essentially all of the gene expression changes that required the cognate $R$ gene RPS 2 also required NDRl (Sato et al. 2007). However, this study also showed that there were additional genes whose expression required NDR1 but not RPS2. Many of these genes were also PAMP responsive, suggesting a role for NDR1 in the PAMP response. This idea was supported by the subsequent finding that DC3000 $h r c C$ grows to higher titers in $n d r l$ than in wild-type plants (Katagiri and Sato 2007). Here, we found that essentially all SA-dependent genes were also $N D R l$-dependent, as were many SA-independent genes. This may reflect a role for $R$ genes in activating responses to ES4326 or it may reflect a general role for NDR1 in SA signaling and a branch of PAD4- and EDS1-dependent signaling. Profiling of $n d r l$ plants after treatment with exogenous SA might help to resolve these possibilities.

Table 4. Pairwise correlations between mutants ${ }^{\mathrm{a}}$

\begin{tabular}{|c|c|c|c|c|c|c|c|c|c|c|c|c|}
\hline & coil & dde 2 & eds 1 & eds 5 & fmol & jin1 & jarl & $n d r 1$ & nprl & pad4 & pbs 3 & sid2 \\
\hline coil & 1 & -0.17 & 0.06 & -0.21 & -0.06 & 0.28 & 0.15 & -0.01 & -0.16 & 0.13 & -0.19 & -0.19 \\
\hline dde 2 & -0.17 & 1 & -0.04 & 0.04 & 0.08 & 0.23 & 0.58 & -0.11 & -0.06 & -0.15 & -0.14 & 0.04 \\
\hline$e d s 1$ & 0.06 & -0.04 & 1 & 0.35 & 0.22 & -0.09 & 0.11 & 0.79 & 0.45 & 0.84 & 0.59 & 0.23 \\
\hline$e d s 5$ & -0.21 & 0.04 & 0.35 & 1 & 0.03 & -0.12 & 0.06 & 0.29 & 0.84 & 0.55 & 0.71 & 0.81 \\
\hline fmol & -0.06 & 0.08 & 0.22 & 0.03 & 1 & -0.06 & -0.04 & 0.27 & 0.02 & 0.16 & 0.11 & -0.03 \\
\hline jin1 & 0.28 & 0.23 & -0.09 & -0.12 & -0.06 & 1 & 0.20 & -0.11 & -0.06 & -0.08 & -0.10 & -0.03 \\
\hline jarl & 0.15 & 0.58 & 0.11 & 0.06 & -0.04 & 0.20 & 1 & -0.07 & -0.08 & -0.03 & -0.08 & 0.05 \\
\hline$n d r 1$ & -0.01 & -0.11 & 0.79 & 0.29 & 0.27 & -0.11 & -0.07 & 1 & 0.39 & 0.75 & 0.69 & 0.11 \\
\hline nprl & -0.16 & -0.06 & 0.45 & 0.84 & 0.02 & -0.06 & -0.08 & 0.39 & 1 & 0.70 & 0.71 & 0.78 \\
\hline pad4 & 0.13 & -0.15 & 0.84 & 0.55 & 0.16 & -0.08 & -0.03 & 0.75 & 0.70 & 1 & 0.68 & 0.45 \\
\hline$p b s 3$ & -0.19 & -0.14 & 0.59 & 0.71 & 0.11 & -0.10 & -0.08 & 0.69 & 0.71 & 0.68 & 1 & 0.51 \\
\hline sid 2 & -0.19 & 0.04 & 0.23 & 0.81 & -0.03 & -0.03 & 0.05 & 0.11 & 0.78 & 0.45 & 0.51 & 1 \\
\hline
\end{tabular}

${ }^{a}$ Pairwise correlations for the values of log fold-change of 205 genes for the indicated mutants versus wild-type. Correlations greater than 0.5 are shown in bold type. The uncentered Pearson correlations between the $\log _{2}$ fold-change values of the infected mutant versus infected wild type were calculated for the set of 205 genes significantly altered by a least twofold in infected wild type versus mock-infected wild type, and significantly different in at least one infected mutant relative to infected wild type. 
The phytotoxin coronatine has been suspected to mimic the action of JA since the isolation of coil plants, which are resistant to coronatine and insensitive to JA (Feys et al. 1994). It is now clear that both coronatine and JA-Ile, the active form of JA, act by binding to the F-box protein COI1, thereby promoting degradation of the JAZ repressor proteins (Chini et al. 2007; Katsir et al. 2008; Thines et al. 2007). Expression profiling studies have shown that coronatine has a major effect on host gene expression during $P$. syringae infection (Thilmony et al. 2006), that methyl-JA and coronatine have similar effects on gene expression in tomato (Uppalapati et al. 2005), and that the effects of JA on gene expression depend largely on COIl (Feng et al. 2003). In our work, data from the ATH1 array showed that many gene expression changes depend on COII. Comparison of the
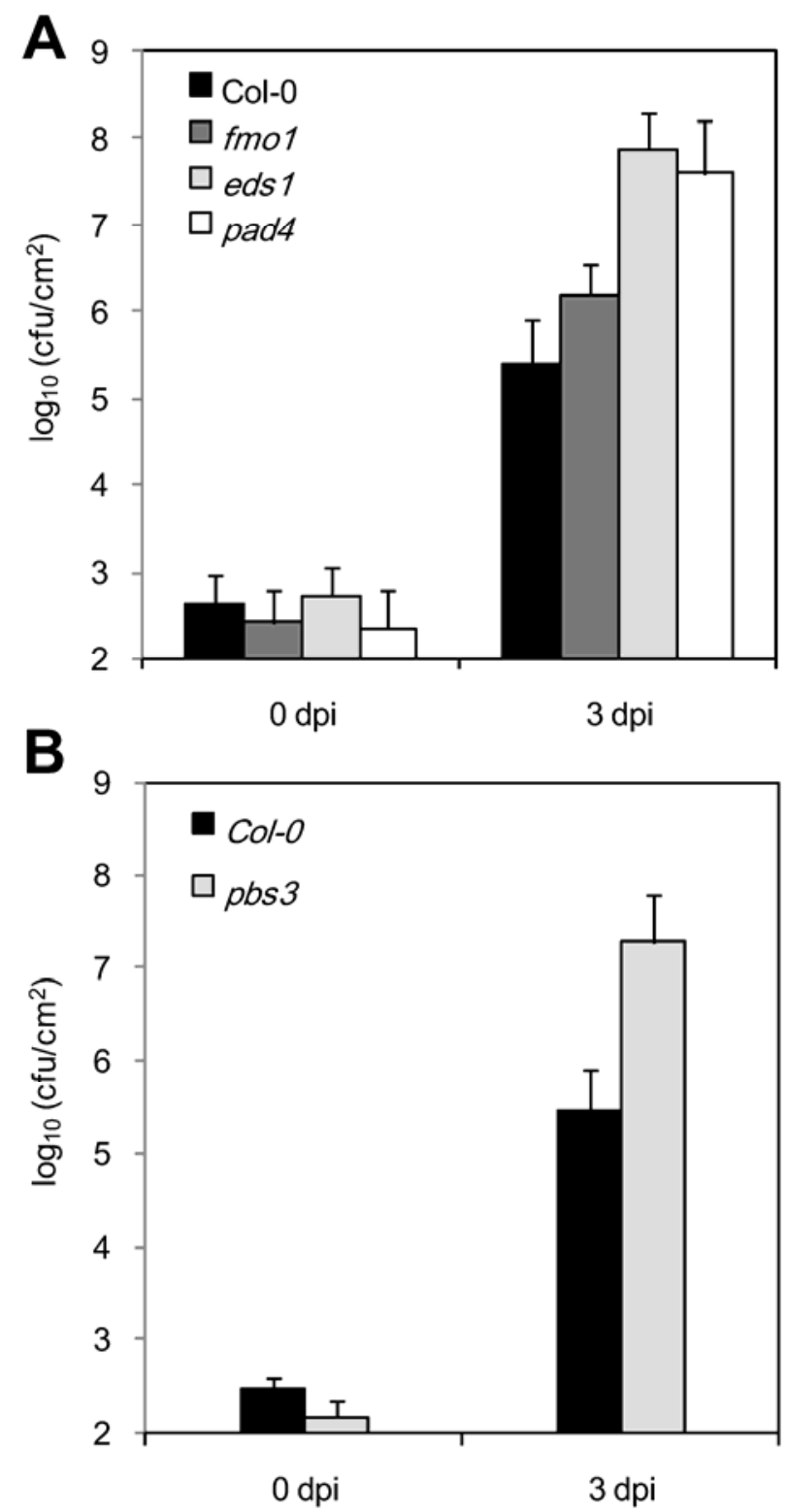

Fig. 5. Growth of Pseudomonas syringae pv. maculicola ES4326 in various genotypes. Plants were inoculated with ES4326 and bacterial titers were determined immediately (0) or 3 days postinoculation (dpi). All four mutants supported significantly higher concentrations of bacteria than the wild type $(P<0.001$ by Mann-Whitney $U$ test). Similar results were obtained in at least three independent experiments. A, Growth in fmol, eds 1 , and pad4. Bars represent means and standard deviations of 4 replicates at $0 \mathrm{dpi}$, and 24, 16, 16, or 8 replicates for the wild type (Col-0), fmol, eds1, and pad4, respectively, at $3 \mathrm{dpi}$. B, Growth in pbs3. Bars represent means and standard deviations of 4 replicates at 0 dpi and 16 replicates at 3 dpi. effects of coil and coronatine deficiency in the pathogen using the miniarray showed that essentially all coil-dependent gene expression changes are attributable to coronatine. Defects in synthesis of endogenous JA had little effect on gene expression.

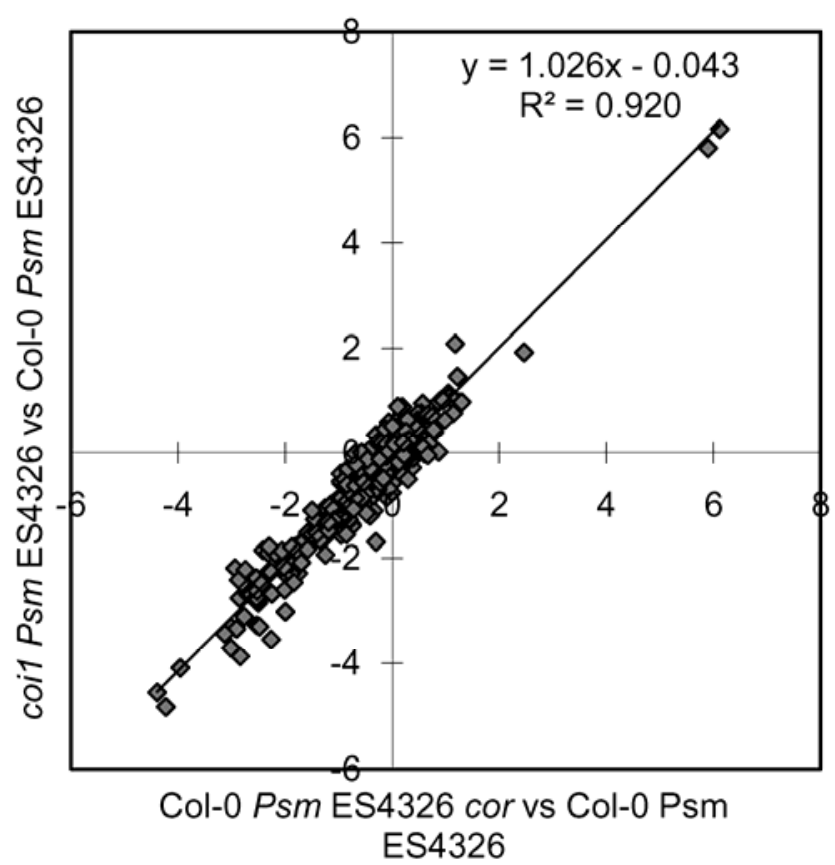

Fig. 6. Presence of coil in the plant or coronatine deficiency in the pathogen have very similar effects. The $\log _{2}$ ratios of infected coil versus infected wild type and wild type infected with Pseudomonas syringae pv. maculicola ES4326 cor versus wild type infected with ES4326 were plotted for all the genes on the miniarray.

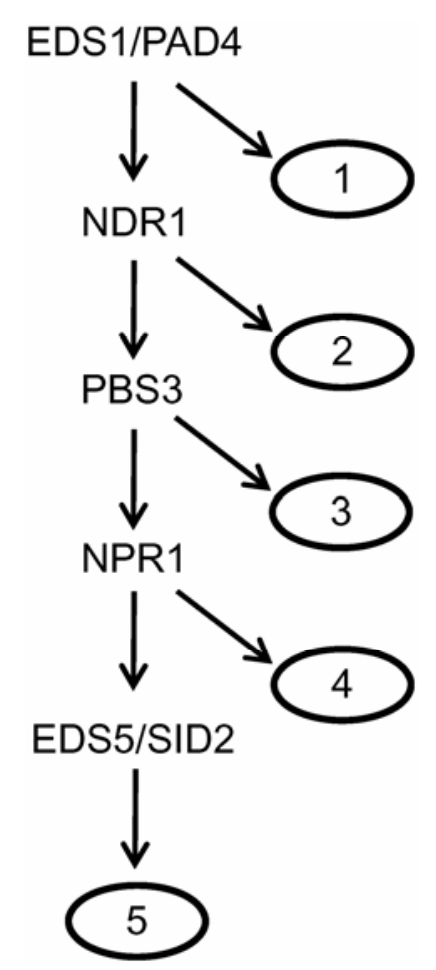

Fig. 7. Model of the network sector including salicylic acid. The model is based mainly on the results from the miniarray, assuming signal divergence as signal proceeds through the network. Numbered ovals represent groups of similarly-regulated genes. Group 4 is based on the results from the ATH1 array. Because this group of genes is not present on the miniarray, the roles of EDS1, PBS3, and NDR1 in their regulation are not directly known. 
Thus, our results show that, in this plant-pathogen interaction, there is very little role for endogenous JA but coronatine produced by the pathogen has a major effect. This result differs from those of Zhao and associates (2003), who did a similar analysis comparing $P$. syringae pv. tomato strains DC3000 and DC3000 cor on wild-type and jail tomato (tomato JAIl is likely orthologous to Arabidopsis COI1). Although there was substantial overlap between coronatine-dependent and JAII-dependent genes, a substantial number of jail-dependent genes were not coronatine dependent (Zhao et al. 2003). There may be more effect of endogenous JA or other oxylipins in the DC3000 tomato system than in the ES4326-Arabidopsis system.

Curiously, among the few genes affected by loss of JA synthesis due to the presence of $d d e 2$, there was a negative correlation between the effect of $d d e 2$ and the effect of coil. This does not appear to be consistent with the fact that coronatine and JA-Ile act similarly in binding to COI1. If the COI1-coronatine complex is more active than the COI1-JA-Ile complex, then COI1 binding to JA-Ile might reduce COI1 activity relative to COI1 binding to coronatine, explaining our results.

In summary, we have investigated the relationships among defense signaling network components defined by mutations using expression profiles as detailed descriptions of mutant phenotypes. It is worth emphasizing that, in this approach, we do not assume that the transcript level of a particular gene represents its activity. Rather, we use causal relationships between the presence of a mutation and changes in the expression profile. Although our analysis at this stage was mostly limited to qualitative comparisons of gene sets that are differentially regulated in single mutants, we succeeded in revealing complex relationships among network components that affect the SA sector. This approach has the potential to extract additional information about the network. It has been shown that even low-amplitude profiles can contain statistically significant information when whole profiles are used as phenotypes (Hughes et al. 2000). Therefore, quantitative analysis of these data could reveal more subtle relationships among network components. The data in this study were generated under a single experimental condition: $24 \mathrm{~h}$ after infection by ES4326. A different pathogen, such as a necrotrophic fungal pathogen, might induce different signal flow patterns in the network and reveal relationships that may have escaped detection using ES4326. Data from multiple timepoints would allow the direction of signal flow to be determined and might reveal relationships that are undetectable at the single timepoint we used.

\section{MATERIALS AND METHODS}

\section{Plant genotypes and growth conditions.}

All genotypes were derived from the Col- 0 accession. They were sid2-2 (Wildermuth et al. 2001), eds5-1 (Nawrath et al. 2002), pad4-1 (Jirage et al. 1999), ein2-1 (Alonso et al. 1999), coil-1 (Xie et al. 1998), ndrl-1 (Century et al. 1997), dde2-2 (von Malek et al. 2002), jarl-1 (Staswick et al. 2002), and jin1-1 (Berger et al. 1996; Lorenzo et al. 2004). The edsl plants were derived by introgression of edsl-2 into Col-0 (Bartsch et al. 2006), fmol-1 was SALK_026163 (Bartsch et al. 2006), and pbs3-2 was SALK_018225 (Nobuta et al. 2007). All plants were grown in controlled-environment chambers at $22^{\circ} \mathrm{C}$ and $75 \%$ relative humidity with $12 \mathrm{~h}$ of light $\left(100 \mu \mathrm{M} \mathrm{m}^{-2} \mathrm{~s}^{-1}\right.$ fluorescent illumination) and $12 \mathrm{~h}$ of darkness.

\section{P. syringae pv. maculicola ES4326 infection and SA assays.}

Pseudomonas syringae pv. maculicola was cultured in King's B medium at room temperature $\left(22\right.$ to $\left.25^{\circ} \mathrm{C}\right)$ as described (Glazebrook and Ausubel 1994). For microarray experiments, overnight liquid cultures were washed and resuspended in 5
$\mathrm{mM} \mathrm{MgSO}_{4}$. Bacteria were diluted to a concentration equivalent to an optical density at $600 \mathrm{~nm}\left(\mathrm{OD}_{600}\right)=0.002$ and introduced into leaves of 30-day-old plants using a needleless syringe. Mock-infected plants were similarly treated with $5 \mathrm{mM}$ $\mathrm{MgSO}_{4}$. For bacterial growth experiments, 4- to 5-week-old plants were inoculated at a concentration of $\mathrm{OD}_{600}=0.0001$. Two leaf discs were cut from each inoculated leaf with a no. 3 cork borer, ground in $5 \mathrm{mM} \mathrm{MgSO}_{4}$, serially diluted, and plated on King's B medium. For free (nonconjugated) SA assays, mature leaves of 4- to 5-week-old plants were inoculated with DC3000 or ES4326 suspensions of $\mathrm{OD}_{600}=0.01$. SA was determined by solid-phase extraction and gas chromatography-mass spectrometry as described previously (Tsuda et al. 2008).

\section{Microarray experiments.}

Microarrays were Affymetrix ATH1 (Redman et al. 2004) and the custom miniarray described previously (Sato et al. 2007). The ATH1 experiments included a sixth mutant, pad2-1. This mutation had relatively little effect on gene expression and it was not discussed here. The data are available from NASCArrays (accession numbers below). The NASC-120 data collected by Nürnberger and associates was obtained from NASCArrays (Craigon et al. 2004). Only the data from the 24-h timepoint was analyzed. Miniarray experiments were conducted in four batches of seven to eight samples each, with three biological replicates of each set. Each batch included wild-type plants inoculated with ES4326 and all sampling was done 24 hpi. Two batches included mock-inoculated wild-type plants. One batch included wild-type and coil plants inoculated with ES4326 or ES4326 cor or mock inoculated. Another batch also included ES4326-inoculated coil plants, making a total of six replicates for this genotype-treatment combination. Some of the genotypes included in the four batches are not relevant to the analysis reported here and, therefore, were not discussed. The complete data sets are available from GEO (accession numbers below). Preparation of RNA, labeling, hybridization to arrays, and scanning were performed as described previously (Sato et al. 2007). ATH1 data generated in this work, as well as NASC-120 data, were normalized using RMAExpress (Irizarry et al. 2003), and miniarray data were normalized using stable genes-based quantile normalization (SBQ) (Sato et al. 2007).

\section{Microarray data analysis.}

Generally, the normalized expression profile data sets were subjected to mixed-effect linear models to obtain the mean estimate and standard error values. The contrast of the second model in each case was set to obtain standard errors for particular comparisons. Student's $t$ test (two tails) was used to obtain the $P$ values for particular comparisons. The $P$ values were corrected for multiple testing using the BenjaminiHochberg FDR, and the corrected values were designated as the $q$ values. All these analyses were done in $\mathrm{R}$ (ver. 2.5.1) using the lme4 package for the mixed models. The models used in each of the following comparisons are described below as cases A, B, and C.

i) Comparison of ES4326-inoculated and mock-inoculated wild-type plants at three timepoints using ATH1 data: case C with two levels of the inoculum effect I, ES4326 and mock inoculation, and three levels of the condition effect $Y, 9,24$, and $32 \mathrm{~h}$.

ii) Comparison of ES4326-inoculated and mock-inoculated wild-type plants at $24 \mathrm{~h}$ using ATH1 data from two experiments: case B with two levels of the sample effect $S$, ES4326 and mock inoculation.

iii) Comparison of wild-type and mutant plants inoculated with ES4326 using ATH1 data: case A with seven levels of the 
sample effect $S$, Col, coil, ein2, npr1, pad2, pad4, and sid2. All the pairwise comparisons among the genotypes were made.

iv) Comparison of pathogen- and mock-inoculated plants in the NASC120 data set: case A with five levels of the sample effect $S$, DC3000, DC3000 avrRpml, DC3000 hrcC, P. syringae pv. phaseolicola, and mock inoculation. Each strain was compared with mock inoculation and all the pairwise comparisons between strains were made.

v) Comparison of ES4326-inoculated and mock-inoculated wild-type plants using miniarray data: case B with two levels of the sample effect $S$, ES4326 and mock inoculation.

vi) Comparison of wild-type and mutant plants inoculated with ES4326 using miniarray data: case B with 22 levels of the sample effect $S$, Col, eds5, nprl, pad4, sid2, coil, dde2, ein2, jinl, jarl, eds1, fmo, ndrl, pbs3, and 8 other genotypes profiled together but not used in this study. Note that this data set did not have a factorial design. Each mutant was compared with Col.

vii) Comparisons using the ES4326 cor data: case $\mathrm{C}$ with two levels of the condition effect, Col and coil, and three levels of the inoculum effect I, ES4326, ES4326 cor, and mock inoculation.

Case A: for data generated as three biological replicates within a single experimental set:

$$
\log _{2}\left(y_{g s r}\right)=\mu+R_{r}+\gamma_{g s r}
$$

And then, for each $g$ th gene, the next model was fit separately:

$$
\gamma_{g s r}=G g+G: S_{g s}+G: R_{g r}+\varepsilon_{g s r},
$$

where $y, \mu, v, R, \gamma, G, S$, and $\varepsilon$ represent expression value, a constant, a constant, replicate, residual from the first model, gene, sample, and residual from the second model, respectively. $R, \gamma$, and $\varepsilon$ were random effects and the rest were fixed effects.

Case B: for data generated in multiple experimental sets, each having three biological replicates:

$$
\log _{2}\left(y_{g s r b}\right)=\mu+B_{b}+B: R_{b r}+\gamma_{g s r b}
$$

And then, for each $g$ th gene, the next model was fit separately:

$$
\gamma_{g s r}=G g+G: S_{g s}+G:(B+B: R)_{g r b}+\varepsilon_{g s r},
$$

where $y, \mu, G g, B, R, \gamma, G, S$, and $\varepsilon$ represent expression value, a constant, a constant, experiment, replicate, residual from the first model, gene, sample, and residual from the second model, respectively. $B, R, \gamma$, and $\varepsilon$ were random effects and the rest were fixed effects. $R$ was nested in $B$.

Case $\mathrm{C}$ : for comparisons with two fixed factors:

$$
\log _{2}\left(y_{\text {gyir }}\right)=\mu+R_{r}+\gamma_{\text {gyir }}
$$

And then, for each $g$ th gene, the next model was fit separately:

$$
\gamma_{g y i r}=G g+G: Y_{g y}+G: Y: I_{g y i}+G: R_{g r}+\varepsilon_{g y i r},
$$

where $y, \mu, G g, R, \gamma, G, Y, I$, and $\varepsilon$ represent expression value, a constant, replicate, residual from the first model, gene, condition, inoculum, and residual from the second model, respectively. $R, \gamma$, and $\varepsilon$ were random effects and the rest were fixed effects.

All correlation values are uncentered Pearson correlations.

\section{Clustering.}

Figure 4 was created by clustering of the $\log _{2}$ fold-change values of mutants versus Col-0. The set of 205 miniarray genes significantly affected by ES4326 infection of wild-type plants $(q<0.05)$ and significantly different in at least one mutation in the study set relative to Col- $0(q<0.05)$ were subjected to complete linkage hierarchical clustering of only the mutants, using Cluster (Eisen et al. 1998). This provided the order and dendrogram for the mutants. Then, the set of 205 genes was separated into the set of genes induced by ES4326 infection of Col-0, and the set repressed. Each set of genes was subjected to complete linkage hierarchical clustering of only the genes. This provided the order and dendrograms for the genes. The $\log _{2}$ fold-change values for Col- 0 versus mock were scaled by a factor of 0.4 and added as the last column of the figure. Note that these values played no part in the clustering.

\section{Microarray data accession numbers.}

The original (.CEL) data files for the 18 ATH1 hybridizations from the ES4326 timecourse experiment are available from NASC Arrays as NASC-414. The files for the 21 ATH1 hybridizations from the wild-type and mutants comparison are available as NASC-454 (accession number pending). The miniarray files are available from Gene Expression Omnibus as GSE11009.

\section{ACKNOWLEDGMENTS}

We thank J. Parker for fmo1-1 and Col eds 1-2 seed, R. Innes for pbs3-2 seed, K. Vernick for use of his GenePix 4000B scanner, the Stanford Functional Genomics Facility for microarray printing, the Minnesota Supercomputing Institute for access to high-performance computers and GENEPIX software, and the University of Minnesota Biomedical Genomics Center for ATH1 hybridization and scanning. This work was supported by grant IOB-0419648 from the National Science Foundation Arabidopsis 2010 program to J. Glazebrook and F. Katagiri. J. D. Cohen was supported by the National Research Initiative (NRI) Plant Biology: Biochemistry of the United States Department of Agriculture Cooperative State Research, Education, and Extension Service (CSREES, grant number 2005-3531816197). R. M. Mitra was supported by a National Institutes of Health postdoctoral fellowship. M. Sato was supported by a Research Fellowship of the Japan Society for the Promotion of Science for Young Scientists.

\section{LITERATURE CITED}

Aarts, N., Metz, M., Holub, E., Staskawicz, B. J., Daniels, M. J., and Parker, J. E. 1998. Different requirements for EDS1 and NDR1 by disease resistance genes define at least two $\mathrm{R}$ gene-mediated signaling pathways in Arabidopsis. Proc. Natl. Acad. Sci. U.S.A. 95:10306-10311.

Alonso, J. M., Hirayama, T., Roman, G., Nourizadeh, S., and Ecker, J. R. 1999. EIN2, a bifunctional transducer of ethylene and stress responses in Arabidopsis. Science 284:2148-2152.

Asai, T., Tena, G., Plotnikova, J., Willmann, M. R., Chiu, W. L., GomezGomez, L., Boller, T., Ausubel, F. M., and Sheen, J. 2002. MAP kinase signaling cascade in Arabidopsis innate immunity. Nature 415:977-983.

Bartsch, M., Gobbato, E., Bednarek, P., Debey, S., Schultze, J. L., Bautor, J., and Parker, J. E. 2006. Salicylic acid-independent ENHANCED DISEASE SUSCEPTIBILITY1 signaling in Arabidopsis immunity and cell death is regulated by the monooxygenase FMO1 and the Nudix hydrolase NUDT7. Plant Cell 18:1038-1051.

Berger, S., Bell, E., and Mullet, J. E. 1996. Two methyl jasmonateinsensitive mutants show altered expression of AtVsp in response to methyl jasmonate and wounding. Plant Physiol. 111:525-531.

Brooks, D. M., Bender, C. L., and Kunkel, B. N. 2005. The Pseudomonas syringae phytotoxin coronatine promotes virulence by overcoming salicylic acid-dependent defences in Arabidopsis thaliana. Mol. Plant Pathol. 6:629-639.

Cao, H., Glazebrook, J., Clarke, J. D., Volko, S., and Dong, X. 1997. The Arabidopsis NPR1 gene that controls systemic acquired resistance encodes a novel protein containing ankyrin repeats. Cell 88:57-63.

Century, K. S., Holub, E. B., and Staskawicz, B. J. 1995. NDR1, a locus of Arabidopsis thaliana that is required for disease resistance to both a bacterial and a fungal pathogen. Proc. Natl. Acad. Sci. U.S.A. 92:6597-6601.

Century, K. S., Shapiro, A. D., Repetti, P. P., Dahlbeck, D., Holub, E., and Staskawicz, B. J. 1997. NDR1, a pathogen-induced component required for Arabidopsis disease resistance. Science 278:1963-1965.

Chinchilla, D., Zipfel, C., Robatzek, S., Kemmerling, B., Nurnberger, T., Jones, J. D., Felix, G., and Boller, T. 2007. A flagellin-induced complex of the receptor FLS2 and BAK1 initiates plant defence. Nature 448:497-500.

Chini, A., Fonseca, S., Fernandez, G., Adie, B., Chico, J. M., Lorenzo, O., Garcia-Casado, G., Lopez-Vidriero, I., Lozano, F. M., Ponce, M. R., Micol, J. L., and Solano, R. 2007. The JAZ family of repressors is the missing link in jasmonate signaling. Nature 448:666-671. 
Craigon, D. J., James, N., Okyere, J., Higgins, J., Jotham, J., and May, S. 2004. NASCArrays: A repository for microarray data generated by NASC's transcriptomics service. Nucleic Acids Res. 32:D575-577.

Despres, C., DeLong, C., Glaze, S., Liu, E., and Fobert, P. R. 2000. The Arabidopsis NPR1/NIM1 protein enhances the DNA binding activity of a subgroup of the TGA family of bZIP transcription factors. Plant Cell $12: 279-290$

de Torres-Zabala, M., Truman, W., Bennett, M. H., Lafforgue, G., Mansfield, J. W., Rodriguez Egea, P., Bogre, L., and Grant, M. 2007. Pseudomonas syringae pv. tomato hijacks the Arabidopsis abscisic acid signaling pathway to cause disease. EMBO (Eur. Mol. Biol. Organ.) J. 26:1434-1443.

Dong, X. 2004. NPR1, all things considered. Curr. Opin. Plant Biol. 7:547-552.

Eisen, M. B., Spellman, P. T., Brown, P. O., and Botstein, D. 1998. Cluster analysis and display of genome-wide expression patterns. Proc. Natl. Acad. Sci. U.S.A. 95:14863-14868

Falk, A., Feys, B. J., Frost, L. N., Jones, J. D., Daniels, M. J., and Parker, J. E. 1999. EDS1, an essential component of $R$ gene-mediated disease resistance in Arabidopsis has homology to eukaryotic lipases. Proc. Natl. Acad. Sci. U.S.A. 96:3292-3297.

Feng, S., Ma, L., Wang, X., Xie, D., Dinesh-Kumar, S. P., Wei, N., and Deng, X. W. 2003. The COP9 signalosome interacts physically with SCFCOI 1 and modulates jasmonate responses. Plant Cell 15:1083-1094.

Feys, B. J., Moisan, L. J., Newman, M. A., and Parker, J. E. 2001. Direct interaction between the Arabidopsis disease resistance signaling proteins, EDS1 and PAD4. EMBO (Eur. Mol. Biol. Organ.) J. 20:5400-5411.

Feys, B. J., Wiermer, M., Bhat, R. A., Moisan, L. J., Medina-Escobar, N., Neu, C., Cabral, A., and Parker, J. E. 2005. Arabidopsis SENESCENCE-ASSOCIATED GENE101 stabilizes and signals within an ENHANCED DISEASE SUSCEPTIBILITY1 complex in plant innate immunity. Plant Cell 17:2601-2613.

Feys, B. J. F., Benedetti, C. E., Penfold, C. N., and Turner, J. G. 1994 Arabidopsis mutants selected for resistance to the phytotoxin coronatine are male sterile, insensitive to methyl jasmonate, and resistant to a bacterial pathogen. Plant Cell 6:751-759.

Glazebrook, J. 2005. Contrasting mechanisms of defense against biotrophic and necrotrophic pathogens. Annu. Rev. Phytopathol. 43:205-227.

Glazebrook, J., and Ausubel, F. M. 1994. Isolation of phytoalexin-deficient mutants of Arabidopsis thaliana and characterization of their interactions with bacterial pathogens. Proc. Natl. Acad. Sci. U.S.A. 91:8955-8959.

Glazebrook, J., Rogers, E. E., and Ausubel, F. M. 1996. Isolation of Arabidopsis mutants with enhanced disease susceptibility by direct screening. Genetics 143:973-982.

Glazebrook, J., Chen, W., Estes, B., Chang, H. S., Nawrath, C., Metraux, J. P., Zhu, T., and Katagiri, F. 2003. Topology of the network integrating salicylate and jasmonate signal transduction derived from global expression phenotyping. Plant J. 34:217-228.

Gomez-Gomez, L., and Boller, T. 2000. FLS2: An LRR receptor-like kinase involved in the perception of the bacterial elicitor flagellin in Arabidopsis. Mol. Cell 5:1003-1011.

Ham, J. H., Kim, M. G., Lee, S. Y., and Mackey, D. 2007. Layered basal defenses underlie non-host resistance of Arabidopsis to Pseudomonas syringae pv. phaseolicola. Plant J. 51:604-616.

Heese, A., Hann, D. R., Gimenez-Ibanez, S., Jones, A. M., He, K., Li, J., Schroeder, J. I., Peck, S. C., and Rathjen, J. P. 2007. The receptor-like kinase SERK3/BAK1 is a central regulator of innate immunity in plants. Proc. Natl. Acad. Sci. U.S.A. 104:12217-12222.

Hughes, T. R., Marton, M. J., Jones, A. R., Roberts, C. J., Stoughton, R., Armour, C. D., Bennett, H. A., Coffey, E., Dai, H., He, Y. D., Kidd, M. J., King, A. M., Meyer, M. R., Slade, D., Lum, P. Y., Stepaniants, S. B., Shoemaker, D. D., Gachotte, D., Chakraburtty, K., Simon, J., Bard, M., and Friend, S. H. 2000. Functional discovery via a compendium of expression profiles. Cell 102:109-126.

Irizarry, R. A., Hobbs, B., Collin, F., Beazer-Barclay, Y. D., Antonellis, K J., Scherf, U., and Speed, T. P. 2003. Exploration, normalization, and summaries of high density oligonucleotide array probe level data. Biostatistics 4:249-264.

Jagadeeswaran, G., Raina, S., Acharya, B. R., Maqbool, S. B., Mosher, S. L., Appel, H. M., Schultz, J. C., Klessig, D. F., and Raina, R. 2007. Arabidopsis GH3-LIKE DEFENSE GENE 1 is required for accumulation of salicylic acid, activation of defense responses and resistance to Pseudomonas syringae. Plant J. 51:234-246.

Jirage, D., Tootle, T. L., Reuber, T. L., Frost, L. N., Feys, B. J., Parker, J. E., Ausubel, F. M., and Glazebrook, J. 1999. Arabidopsis thaliana PAD4 encodes a lipase-like gene that is important for salicylic acid signaling. Proc. Natl. Acad. Sci. U.S.A. 96:13583-13588.

Jones, J. D., and Dangl, J. L. 2006. The plant immune system. Nature 444:323-329
Katagiri, F., and Sato, M. 2007. Expression profiles as detailed snapshots of biological states. Transgenic Res. 16:399-403

Katsir, L., Schilmiller, A. L., Staswick, P. E., He, S. Y., and Howe, G. A. 2008. COI1 is a critical component of a receptor for jasmonate and the bacterial virulence factor coronatine. Proc. Natl. Acad. Sci. U.S.A. 105:7100-7105.

Kinkema, M., Fan, W., and Dong, X. 2000. Nuclear localization of NPR1 is required for activation of PR gene expression. Plant Cell 12:2339-2350.

Lee, M. W., Lu, H., Jung, H. W., and Greenberg, J. T. 2007. A key role for the Arabidopsis WIN3 protein in disease resistance triggered by Pseudomonas syringae that secrete AvrRpt2. Mol. Plant-Microbe Interact. 20:1192-1200

Li, J., Brader, G., Palva, E. T. 2004. The WRKY70 transcription factor: A node of convergence for jasmonate-mediated and salicylate-mediated signals in plant defense. Plant Cell 16:319-331.

Li, J., Brader, G., Kariola, T., and Tapio Palva, E. 2006. WRKY70 modulates the selection of signaling pathways in plant defense. Plant $\mathrm{J}$. 46:477-491.

Lorenzo, O., Chico, J. M., Sanchez-Serrano, J. J., and Solano, R. 2004. JASMONATE-INSENSITIVE1 encodes a MYC transcription factor essential to discriminate between different jasmonate-regulated defense responses in Arabidopsis. Plant Cell 16:1938-1950.

McDowell, J. M., Cuzick, A., Can, C., Beynon, J., Dangl, J. L., and Holub, E. B. 2000. Downy mildew (Peronospora parasitica) resistance genes in Arabidopsis vary in functional requirements for NDR1, EDS1, NPR1 and salicylic acid accumulation. Plant J. 22:523-529.

Melotto, M., Underwood, W., Koczan, J., Nomura, K., and He, S. Y. 2006. Plant stomata function in innate immunity against bacterial invasion. Cell 126:969-980.

Mishina, T. E., and Zeier, J. 2006. The Arabidopsis flavin-dependent monooxygenase FMO1 is an essential component of biologically induced systemic acquired resistance. Plant Physiol. 141:1666-1675.

Mou, Z., Fan, W., and Dong, X. 2003. Inducers of plant systemic acquired resistance regulate NPR1 function through redox changes. Cell 113:935-944.

Mur, L. A., Kenton, P., Atzorn, R., Miersch, O., and Wasternack, C. 2006. The outcomes of concentration-specific interactions between salicylate and jasmonate signaling include synergy, antagonism, and oxidative stress leading to cell death. Plant Physiol. 140:249-262.

Navarro, L., Zipfel, C., Rowland, O., Keller, I., Robatzek, S., Boller, T. and Jones, J. D. 2004. The transcriptional innate immune response to flg22. Interplay and overlap with $A v r$ gene-dependent defense responses and bacterial pathogenesis. Plant Physiol. 135:1113-1128.

Navarro, L., Dunoyer, P., Jay, F., Arnold, B., Dharmasiri, N., Estelle, M., Voinnet, O., and Jones, J. D. 2006. A plant miRNA contributes to antibacterial resistance by repressing auxin signaling. Science 312:436-439.

Nawrath, C., and Metraux, J. P. 1999. Salicylic acid induction-deficient mutants of Arabidopsis express PR-2 and PR-5 and accumulate high levels of camalexin after pathogen inoculation. Plant Cell 11:1393-1404.

Nawrath, C., Heck, S., Parinthawong, N., and Metraux, J. P. 2002. EDS5, an essential component of salicylic acid-dependent signaling for disease resistance in Arabidopsis, is a member of the MATE transporter family. Plant Cell 14:275-286

Nishimura, M. T., Stein, M., Hou, B. H., Vogel, J. P., Edwards, H., and Somerville, S. C. 2003. Loss of a callose synthase results in salicylic acid-dependent disease resistance. Science 301:969-972.

Nobuta, K., Okrent, R. A., Stoutemyer, M., Rodibaugh, N., Kempema, L., Wildermuth, M. C., and Innes, R. W. 2007. The GH3 acyl adenylase family member PBS3 regulates salicylic acid-dependent defense responses in Arabidopsis. Plant Physiol. 144:1144-1156.

Petersen, M., Brodersen, P., Naested, H., Andreasson, E., Lindhart, U., Johansen, B., Nielsen, H. B., Lacy, M., Austin, M. J., Parker, J. E., Sharma, S. B., Klessig, D. F., Martienssen, R., Mattsson, O., Jensen, A. B., and Mundy, J. 2000. Arabidopsis map kinase 4 negatively regulates systemic acquired resistance. Cell 103:1111-1120.

Pieterse, C. M., van Wees, S. C., van Pelt, J. A., Knoester, M., Laan, R., Gerrits, H., Weisbeek, P. J., and van Loon, L. C. 1998. A novel signaling pathway controlling induced systemic resistance in Arabidopsis. Plant Cell 10:1571-1580.

Redman, J. C., Haas, B. J., Tanimoto, G., and Town, C. D. 2004. Development and evaluation of an Arabidopsis whole genome Affymetrix probe array. Plant J. 38:545-561.

Robert-Seilaniantz, A., Navarro, L., Bari, R., and Jones, J. D. 2007. Pathological hormone imbalances. Curr. Opin. Plant Biol. 10:372-379.

Sato, M., Mitra, R. M., Coller, J., Wang, D., Spivey, N. W., Dewdney, J., Denoux, C., Glazebrook, J., and Katagiri, F. 2007. A high-performance, small-scale microarray for expression profiling of many samples in Arabidopsis -pathogen studies. Plant J. 49:565-577.

Schenk, P. M., Kazan, K., Wilson, I., Anderson, J. P., Richmond, T., Somerville, S. C., and Manners, J. M. 2000. Coordinated plant defense 
responses in Arabidopsis revealed by microarray analysis. Proc. Natl. Acad. Sci. U.S.A. 97:11655-11660.

Staswick, P. E., and Tiryaki, I. 2004. The oxylipin signal jasmonic acid is activated by an enzyme that conjugates it to isoleucine in Arabidopsis. Plant Cell 16:2117-2127.

Staswick, P. E., Tiryaki, I., and Rowe, M. L. 2002. Jasmonate response locus JAR1 and several related Arabidopsis genes encode enzymes of the firefly luciferase superfamily that show activity on jasmonic, salicylic, and indole-3-acetic acids in an assay for adenylation. Plant Cell 14:1405-1415.

Thilmony, R., Underwood, W., and He, S. Y. 2006. Genome-wide transcriptional analysis of the Arabidopsis thaliana interaction with the plant pathogen Pseudomonas syringae pv. tomato DC3000 and the human pathogen Escherichia coli O157:H7. Plant J. 46:34-53.

Thines, B., Katsir, L., Melotto, M., Niu, Y., Mandaokar, A., Liu, G., Nomura K., He, S. Y., Howe, G. A., and Browse, J. 2007. JAZ repressor proteins are targets of the SCFCOI1 complex during jasmonate signaling. 448:661-665.

Truman, W., Zabala, M. T., and Grant, M. 2006. Type III effectors orchestrate a complex interplay between transcriptional networks to modify basal defence responses during pathogenesis and resistance. Plant J. 46:14-33.

Tsuda, K., Sato, M., Glazebrook, J., Cohen, J. D., and Katagiri, F. 2008 Interplay between MAMP-triggered and SA-mediated defense responses. Plant J. 53:763-775.

Uppalapati, S. R., Ayoubi, P., Weng, H., Palmer, D. A., Mitchell, R. E., Jones, W., and Bender, C. L. 2005. The phytotoxin coronatine and methyl jasmonate impact multiple phytohormone pathways in tomato. Plant J. 42:201-217.

Volko, S. M., Boller, T., and Ausubel, F. M. 1998. Isolation of new Arabidopsis mutants with enhanced disease susceptibility to Pseudomonas syringae by direct screening. Genetics 149:537-548.

von Malek, B., van der Graaff, E., Schneitz, K., and Keller, B. 2002. The Arabidopsis male-sterile mutant dde2-2 is defective in the ALLENE OXIDE SYNTHASE gene encoding one of the key enzymes of the jasmonic acid biosynthesis pathway. Planta 216:187-192.

Wang, D., Amornsiripanitch, N., and Dong, X. 2006. A genomic approach to identify regulatory nodes in the transcriptional network of systemic acquired resistance in plants. PLoS Pathogens 2:e123.

Wasternack, C. 2007. Jasmonates: An update on biosynthesis, signal transduction and action in plant stress response, growth and development. Ann. Bot. 100:681-697.

Wiermer, M., Feys, B. J., and Parker, J. E. 2005. Plant immunity: The EDS1 regulatory node. Curr. Opin. Plant Biol. 8:383-389.

Wildermuth, M. C., Dewdney, J., Wu, G., and Ausubel, F. M. 2001. Isochorismate synthase is required to synthesize salicylic acid for plant defence. Nature 414:562-565.

Xie, D. X., Feys, B. F., James, S., Nieto-Rostro, M., and Turner, J. G. 1998. COI1: An Arabidopsis gene required for jasmonate-regulated defense and fertility. Science 280:1091-1094.

Zhang, J., Shao, F., Li, Y., Cui, H., Chen, L., Li, H., Zou, Y., Long, C., Lan, L., Chai, J., Chen, S., Tang, X., and Zhou, J.-M. 2007. A Pseudomonas syringae effector inactivates MAPKs to suppress PAMPinduced immunity in plants. Cell Host Microbe 1:175-185.

Zhang, Y., Fan, W., Kinkema, M., Li, X., and Dong, X. 1999. Interaction of NPR1 with basic leucine zipper protein transcription factors that bind sequences required for salicylic acid induction of the $P R-1$ gene. Proc. Natl. Acad. Sci. U.S.A. 96:6523-6528.

Zhao, Y., Thilmony, R., Bender, C. L., Schaller, A., He, S. Y., and Howe, G. A. 2003. Virulence systems of Pseudomonas syringae pv. tomato promote bacterial speck disease in tomato by targeting the jasmonate signaling pathway. Plant J. 36:485-499.

Zhou, N., Tootle, T. L., Tsui, F., Klessig, D. F., and Glazebrook, J. 1998 $P A D 4$ functions upstream from salicylic acid to control defense responses in Arabidopsis. Plant Cell 10:1021-1030.

Zipfel, C., Robatzek, S., Navarro, L., Oakeley, E. J., Jones, J. D., Felix, G., and Boller, T. 2004. Bacterial disease resistance in Arabidopsis through flagellin perception. Nature 428:764-767.

\section{AUTHOR-RECOMMENDED INTERNET RESOURCES}

Nottingham Arabidopsis Stock Centre (NASC) arrays: affymetrix.arabidopsis.info

National Center for Biotechnology Information Gene Expression Omnibus: www.ncbi.nlm.nih.gov/geo 